\title{
CASE REPORT: ADRENAL PHAEOCHROMOCYTOMA PRESENTING WITH ILEUS, RENAL VEIN THROMBOSIS AND PULMONARY EMBOLISM
}

\section{Lai R, Lee D, Liew HL, Quek TPL, Seow CJ}

Introduction Phaechromocytomas are catecholamine-secreting neuroendocrine tumours arising from chromaffin cells in the adrenal medulla. They
may potentially present with a wide variety of symptoms - including, classically, headache, palpitations, diaphoresis, and paroxysmal or Tan Tock Seng sustained hypertension ${ }^{1-2}$. However, making the diagnosis can still be challenging, particularly if the clinical presentation is atypical. We report one such case.

Case Presentation A 56 year old man, previously well, presented to our Emergency Department with a 5-day history of abdominal distension, vomiting, breathlessness, and Case Presentation haemoptysis. He had a preceding history of hypertension, which had been diagnosed one year ago, and for which he was not on treatment. Fig 1 Physical examination revealed a temperature of $38.3^{\circ} \mathrm{C}$, BP $159 / 95 \mathrm{mmHg}$, and sinus tachycardia at HR 126/min. Lung fields were clear to auscultation. The abdomen was distended but non-tender, with hyperactive bowel sounds.

An urgent CT scan of the abdomen revealed gross dilatation of a long segment of small bowel, with a transition point at the distal jejunum. Incidental note was made of a heterogeneous $4.6 \times 4.5 \times 4.9 \mathrm{~cm}$ left adrenal mass, with associated left renal vein thrombosis (Fig 1). The imaged lung bases showed a suggestion of a left lower lobe segmental pulmonary embolism, the presence of which was confirmed on a subsequent CT pulmonary angiogram (Fig 2). Doppler ultrasound of both lower limbs showed no deep venous thrombosis.

The patient underwent an emergent laparotomy and bowel decompression. Intra-operatively, no obstructing bowel lesion was identified. Post-operatively, blood pressure was noted to range up to $200 / 120 \mathrm{mmHg}$, with persistent tachycardia up to $120-140 / \mathrm{min}$ - these improved over the course of 3-4 days with anti-hypertensive treatment (nifedipine) and hydration. Anticoagulation with SC enoxaparin was commenced for venous thromboembolism. The patient recovered well post-operatively and was discharged. Attention was thereafter directed towards evaluation of his left adrenal mass. Adrenal biochemistry, sent 6 days post-operatively, demonstrated urinary metanephrines and normetanephrines elevated over 10 times the normal range (Table 1), supporting the diagnosis of a left adrenal phaeochromocytoma. The patient was switched to phenoxybenzamine for BP control, with atenolol added later.

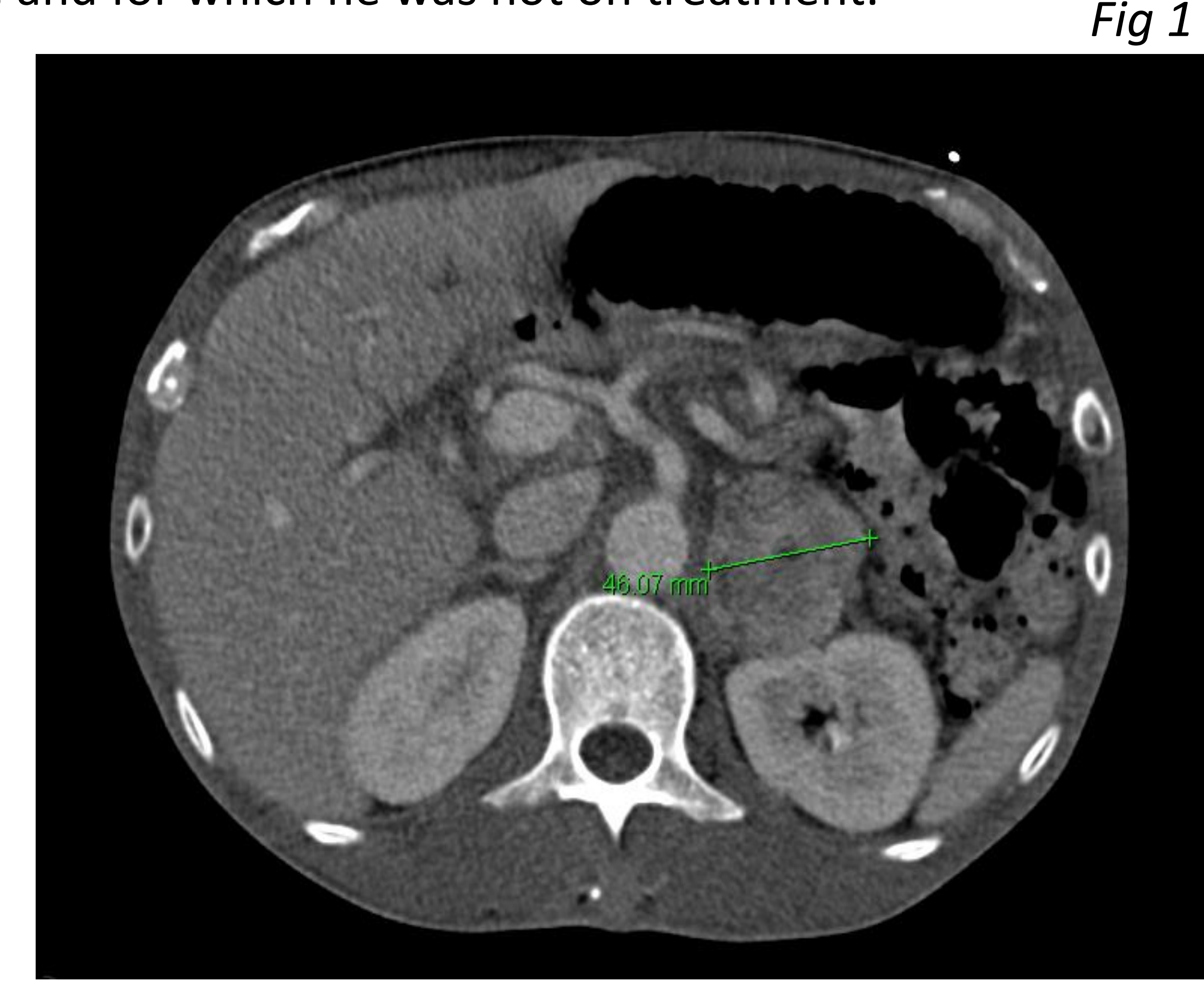

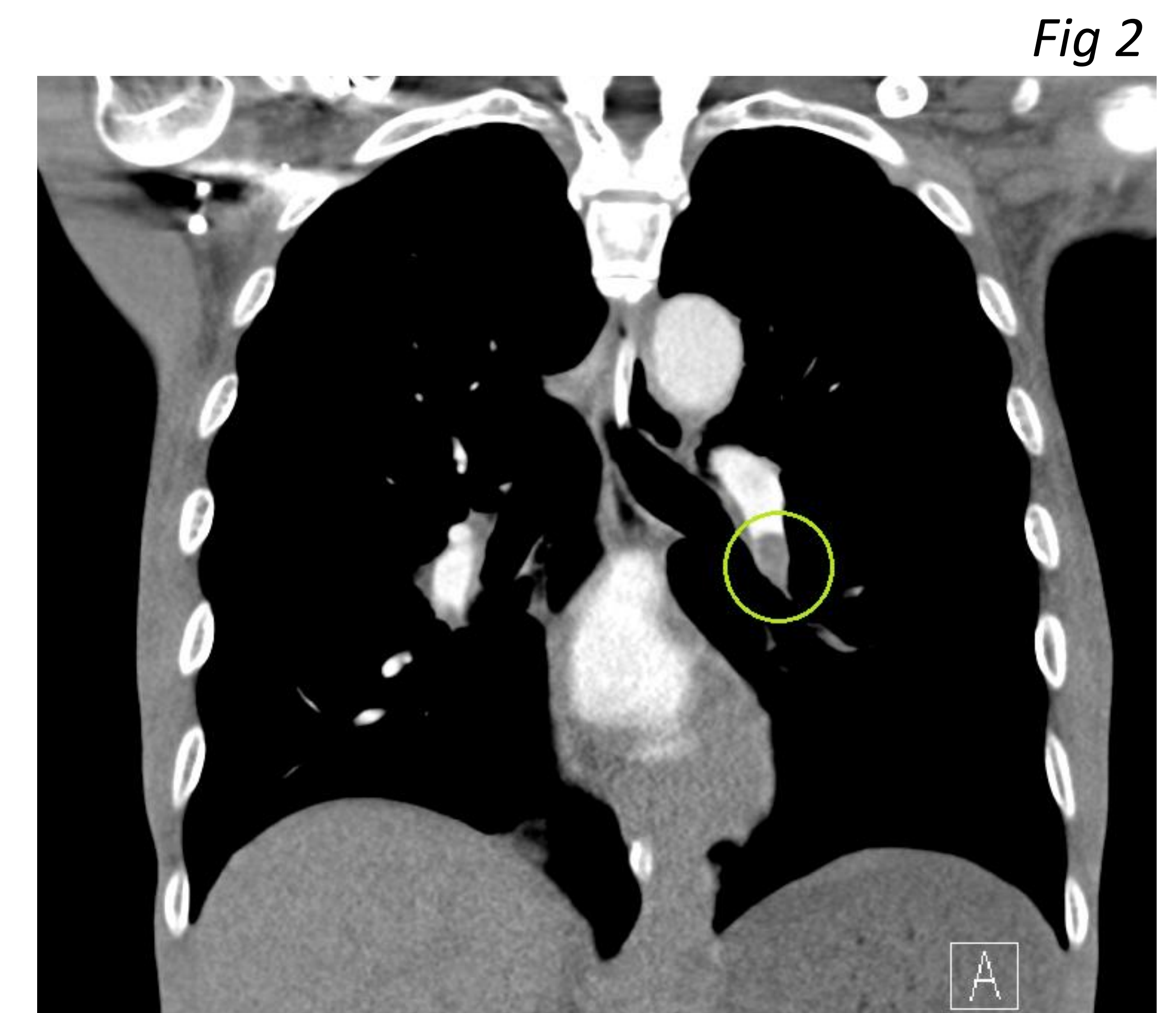

An elective laparoscopic left adrenalectomy was scheduled. Intra-operatively, a $4.0 \times 4.8 \times 3.4 \mathrm{~cm}$ left adrenal tumour, with no extraadrenal invasion into surrounding structures, was identified and resected. Histology was consistent with phaeochromocytoma; no mitotic activity was identified within clusters of tumour cells.

\begin{tabular}{llllll}
\hline Test & Pre-op & POD 3 & POD 15 & 6 wks post-op & Reference Range \\
\hline 24h urinary adrenaline (nmol/day) & 4046 & 45.2 & $<10.0$ & $<10.0$ & $9.3-122$ \\
\hline 24h urinary noradrenaline (nmol/day) & 6707 & 802 & 352 & 203 & $72-505$ \\
\hline 24h urinary metanephrine (nmol/L) & 45232 & 960 & 520 & 298 & $700-2000$ \\
\hline 24h urinary normetanephrine (nmol/L) & 34032 & 4521 & 2014 & 935 & $480-2424$
\end{tabular}

34032

4521

2014

$480-2424$

Post-operative recovery was uneventful, and the patient was discharged stable. His urinary metanephrines and normetanephrines fell to normal by 15 days post-surgery (Table 1). A repeat CT scan of the thorax 6 weeks post-operatively showed complete resolution of the left lower lobe pulmonary embolus. Anticoagulation was discontinued, and blood pressure normalised with maintenance on low-dose bisoprolol and lisinopril. The patient has since remained well.

Discussion

Paralytic ileus and venous thromboembolism are two relatively uncommon simultaneously, as in our patient.

The gastrointestinal effects of phaeochromocytoma may range from mild and non-specific abdomina pain and vomiting ${ }^{1}$ to more severe refractory constipation, ileus, and enterocolitis ${ }^{3-8}$. Catecholamine suppress intestinal motility via direct effects on alpha- and beta-adrenergic receptors in the gut resulting in reduced intestinal tone and peristalsis, and contraction of intestinal sphincters ${ }^{4,6}$. Furthermore, catecholamine-mediated contraction of smooth muscle in the mesenteric vasculature, in combination with increased intestinal metabolic demand, result in bowel ischaemia, which in itself may contribute to dysmotility $4,6-8$

Cases of paralytic ileus associated with phaeochromocytoma have been occasionally reported since the mid-1900s $s^{3-8}$, with ileus usually resolving after tumour resection and/or alpha-blockade ${ }^{3-4,8}$. Th recognition of ileus as a complication of phaeochromocytoma is important, as there is a possibility of progression to bowel infarction and perforation if diagnosis and treatment are delayed ${ }^{4,6-7}$.

In contrast, the haemostatic effect of catecholamine excess has been spotlighted only in more recen literature (Table 2), with several postulated pathophysiological mechanisms.

Firstly, catecholamines exert direct effects on primary and secondary haemostasis ${ }^{9}-$ adrenergic infusions have been shown in-vivo to increase fVIII activity, VWF antigen, tPA activity, and platelet activation and aggregation in a dose-dependent fashion ${ }^{10}$. Conversely, administration of the betablocker propranolol was found in one study to reduce fVIII:C levels in patients with deep vei thrombosis, as compared to untreated controls ${ }^{11}$.

A review of the cases highlighted offers possible alternative explanations for thrombotic phenomena - including direct tumour invasion into the inferior vena cava, arising from a right adrenal tumour ${ }^{12}$ 13,19,22; venous stasis due to extrinsic tumour compression ${ }^{14}$; a prothrombotic state further contributed by malignancy ${ }^{21,29}$ or polycythaemia (arising in one case from tumour secretion of erythropoietin ${ }^{21}$; and catecholamine-induced cardiomyopathy with intracardiac thrombus and thromboembolism 28-30,32,34,36-37.

Nonetheless, there are cases of thrombosis for which these "alternative" mechanisms fail to accoun - for example, intracardiac thrombi without evidence of cardiomyopathy ${ }^{31,33,35}$. This corroborates the likely independent effect of catecholamine excess on systemic hypercoagulability. Our patient, too experienced venous thromboembolism on the background of an apparently benign, moderately-sized umour. While no strong recommendation for prophylactic anticoagulation in phaeochromocytom can yet be made, increased vigilance for arterial and venous thromboembolism in these patient could allow for earlier intervention and the avoidance of morbidity.

In summary, while paralytic leus and thrombotic events are not typically associated with phaeochromocytomas, whis case report underlines their importance as clinically relevant manifestations of catecholamine excess.
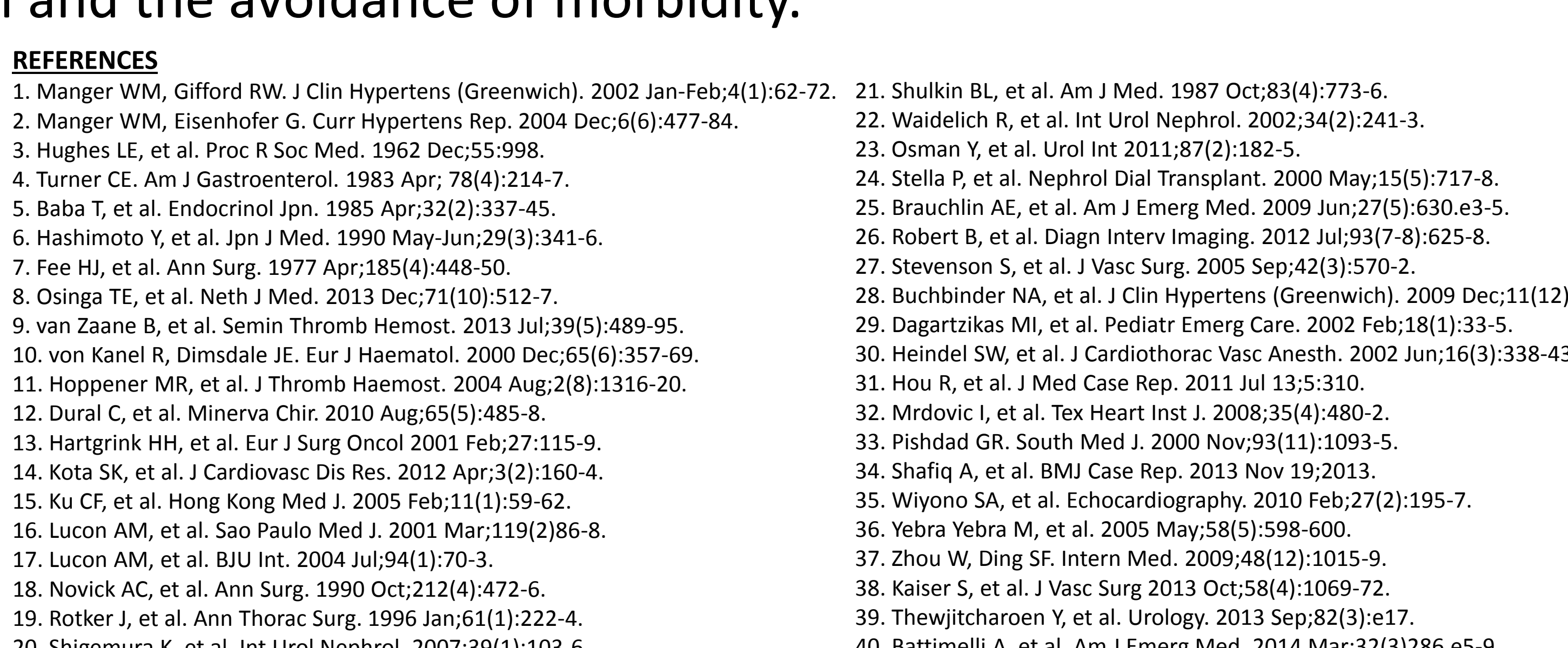

\begin{tabular}{|c|c|c|c|c|}
\hline Case Report & Age & Gender & Tumour location / largest diameter & Arterial thromboembolism / venous \\
\hline Dural $^{12}$ & 17 & M & Right adrenal, $10 \mathrm{~cm}$ & IVC, right atrium \\
\hline Hartgrink $^{13}$ & 38 & $\mathrm{~F}$ & Right adrenal, $16 \mathrm{~cm}$ & $\begin{array}{l}\text { IVC, right atrium } \\
\text { Left latero-basal nulmonarv embolism }\end{array}$ \\
\hline Kota $^{14}$ & 48 & M & Right adrenal, $7.6 \mathrm{~cm}$ & IVC up to confluence of hepatic veins \\
\hline $\mathrm{Ku}^{15}$ & 21 & $\mathrm{~F}$ & Right adrenal, $12 \mathrm{~cm}$ & IVC, right atrium \\
\hline Lucon $^{16}$ & 43 & M & Right adrenal, $6.5 \mathrm{~cm}$ & IVC \\
\hline \multirow[t]{3}{*}{ Lucon $^{17}$} & 46 & M & Right adrenal, 8cm & IVC \\
\hline & 43 & M & Right adrenal, $10.6 \mathrm{~cm}$ & IVC \\
\hline & 24 & $\mathrm{~F}$ & Right adrenal, $5.5 \mathrm{~cm}$ & IVC \\
\hline Novick $^{18}$ & u & $\mathrm{U}$ & Adrenal, details unknown & IVC \\
\hline \multirow[t]{2}{*}{ Rotker $^{19}$} & 51 & M & Right adrenal, $4.3 \mathrm{~cm}$ & IVC \\
\hline & 58 & $\mathrm{~F}$ & Right adrenal - resected 2 yrs prior & IVC, right atrium \\
\hline Shigemura ${ }^{20}$ & 61 & M & Right adrenal, $6.7 \mathrm{~cm}$ & IVC \\
\hline Shulkin ${ }^{21}$ & 31 & M & $\begin{array}{l}\text { Multiple abdominal } \\
\text { phaeochromocytomas }\end{array}$ & $\begin{array}{l}\text { IVC, right common femoral vein, right } \\
\text { inferior epigastric veins }\end{array}$ \\
\hline Waidelich 22 & 78 & $\mathrm{~F}$ & Right adrenal, $8 \mathrm{~cm}$ & IVC, right adrenal vein \\
\hline Osman 23 & u & M & Adrenal, details unknown & Adrenal +/- renal vein \\
\hline Stella ${ }^{24}$ & 38 & M & Right adrenal, 4-5cm & Cerebral venous sinuses \\
\hline Brauchlin 25 & 51 & M & Ectopic (pelvis), recurrent, $8 \mathrm{~cm}$ & Portal vein \\
\hline Robert $^{26}$ & 43 & M & Ectopic (organ of Zuckerkandl), $7 \mathrm{~cm}$ & Superior mesenteric vein \\
\hline Stevenson $^{27}$ & 46 & M & Ectopic (organ of Zuckerkandl), $9 \mathrm{~cm}$ & Left iliofemoral vein \\
\hline Buchbinder $^{28}$ & 49 & M & $\begin{array}{l}\text { Left retroperitoneal paraganglioma, } \\
7.7 \mathrm{~cm}\end{array}$ & $\begin{array}{l}\text { Left renal vein } \\
\text { LV thrombus }(1.3 \times 1.9 \mathrm{~cm}) \\
\text { Stroke } \\
\text { Multiple left renal infarcts }\end{array}$ \\
\hline Dagartzikas $^{29}$ & 13 & M & Left adrenal, $8.5 \mathrm{~cm}$ & $\begin{array}{l}\text { LV thrombus } \\
\text { Right middle cerebral artery } \\
\text { Bilateral acute lower limb ischaemia }\end{array}$ \\
\hline Heindel ${ }^{30}$ & 49 & M & Left adrenal, $10 \mathrm{~cm}$ & $\begin{array}{l}3 \mathrm{LV} \text { thrombi }(0.5-1.0 \mathrm{~cm}) \\
\text { Right cerebellar and cortical infarcts; } \\
\text { right frontal lobe infarct } \\
\text { Right foot ischaemia }\end{array}$ \\
\hline $\mathrm{Hou}^{31}$ & 47 & $\mathrm{~F}$ & Left adrenal, $8 \mathrm{~cm}$ & $\begin{array}{l}\text { "Large" } L \mathrm{~V} \text { thrombus } \\
\text { Left axillary artery }\end{array}$ \\
\hline Mrdovic ${ }^{32}$ & 53 & $\mathrm{~F}$ & Left adrenal, size unknown & “Large" LV apical thrombus \\
\hline Pishdad $^{33}$ & 18 & $\mathrm{~F}$ & Right adrenal, $8 \mathrm{~cm}$ & LV thrombus $(2 \mathrm{~cm})$ \\
\hline Shafiq ${ }^{34}$ & 47 & M & Mediastinal paraganglioma, $5.3 \mathrm{~cm}$ & $\begin{array}{l}2 \mathrm{LV} \text { thrombi }(1.43-1.8 \mathrm{~cm}) \\
\text { Multiterritory (anterior / posterior } \\
\text { circulation) cerebral infarcts }\end{array}$ \\
\hline Wiyono $^{35}$ & 43 & M & Left adrenal, size unknown & “Large” LV thrombus \\
\hline Yebra Yebra ${ }^{36}$ & 59 & M & Left adrenal, $3.5 \mathrm{~cm}$ & $\begin{array}{l}\text { LV thrombus, } 3 \times 0.6 \mathrm{~cm} \\
\text { Left-sided cerebral infarct }\end{array}$ \\
\hline Zhou $^{37}$ & 43 & $\mathrm{~F}$ & Right adrenal, $7 \mathrm{~cm}$ & $\begin{array}{l}\text { LV thrombi }(28 \times 17 \mathrm{~mm}, 0.8 \times 0.7 \mathrm{~mm}) \\
\text { Multiple renal infarcts } \\
\text { Bilateral femoral arteries; peroneal, } \\
\text { anterior / posterior tibial arteries }\end{array}$ \\
\hline Kaiser $^{38}$ & 50 & $\mathrm{~F}$ & Left adrenal, $7.8 \mathrm{~cm}$ & $\begin{array}{l}\text { Right middle cerebral artery } \\
\text { Right distal subclavian to radial artery }\end{array}$ \\
\hline Thewjitcharoen ${ }^{39}$ & 47 & $\mathrm{~F}$ & Right adrenal, size unknown & Right renal artery \\
\hline Battimellit0 & 63 & $\mathrm{~F}$ & Left adrenal, $7 \mathrm{~cm}$ & Right posterior tibial artery \\
\hline
\end{tabular}

